\title{
Perencanaan Sistem Proteksi Generator dari Putaran Balik di PLTMH Totabuan
}

\author{
TEGUH ARFIANTO, NASRUN HARIYANTO, DELFAN TONIUS SITOHANG
}

\author{
Institut Teknologi Nasional Bandung \\ Email : teguh_2000@itenas.ac.id
}

Received 17 Juni 2018 | Revised 26 Agustus 2018 | Accepted 30 September 2018

\begin{abstract}
ABSTRAK
Pada penelitian ini penulis melakukan perhitungan, simulasi dengan aplikasi ETAP 12.6.0 kemudian membandingkan hasil simulasi dengan standar PLN. Pada setting relay daya balik penulis menerapkan standart IEEE C37.102-2006, daya balik generator dengan kapasitas 2 × 2,5 MW adalah 50000 watt dengan waktu tunda relay 10 detik. Sedangkan daya balik untuk generator kapasitas $4 \times 0,7 \mathrm{MW}$ adalah 14000 watt dengan waktu tunda relay 10 detik. Hasil yang didapat dari simulasi saat terjadi kenaikan tegangan $110 \%$ adalah 0,57 detik dan saat $130 \%$ adalah 0,105 detik. Sedangkan untuk setting relay tegangan saat terjadi turun tegangan $50 \%$ adalah 0,125 detik dan saat 80\% adalah 1,25 detik. Hasil simulasi dengan standar PLN tidak jauh berbeda, waktu yang diterapkan PLN ketika naik tegangan $110 \%$ adalah 2 detik dan saat 130\% adalah 0,1 detik kemudian untuk turun tegangan 50\% adalah 0,1 detik dan saat $80 \%$ adalah 1 detik.
\end{abstract}

Kata Kunci: Generator, Daya Balik, Proteksi, Setting, Relay

\begin{abstract}
In this study the authors perform calculations, simulations with software ETAP 12.6.0 and then compare the results of simulation with standard PLN. On setting power relay writer applying standart IEEE C37.102-2006, generator reverse power capacity $2 \times 2.5 \mathrm{MW}$ is 50000 watt with relay time delay 10 second. While reverse power for generator capacity $4 \times 0,7 \mathrm{MW}$ is 14000 watt with a 10 second delay time. The results obtained from simulation when there is a $110 \%$ increase voltage 0.57 seconds and when $130 \%$ is 0.105 seconds. As for the setting of voltage relay when there voltage drop of $50 \%$ is 0.125 seconds and when $80 \%$ is 1.25 seconds. The result of simulation with PLN standard is not much different, the time applied by PLN when the voltage rise of $110 \%$ adds 2 seconds and when $130 \%$ is 0.1 seconds later to drop the 50\% voltage 0.1 second and $80 \%$ is 1 second.
\end{abstract}

Keywords: Generator, Reverse Power, Proteksi, Setting, Relay 


\section{PENDAHULUAN}

PLTMH Totabuan terletak di sungai Dumoga Desa Totabuan Kabupaten Bolaang Mongondow akan masuk ke sistem kotamubagu dengan beban puncak 140,8MW. Generator sangat dibutuhkan sebagai pembangkitan energi listrik. Mengingat fungsinya yang berperan sangat penting dalam pembangkitan listrik baru maka sangat dibutuhkan suatu sistem proteksi yang melindungi peralatan dari gangguan. Misalnya gangguan kehilangan penggerak mula (prime mover) hilang pada saat generator masih terhubung pada jaringan sistem tenaga listrik dan medan penguat masih bekerja, apabila hal ini terjadi maka generator tersebut akan berubah menjadi motor. Bila hal ini dibiarkan maka akan menyebabkan generator mengalami panas berlebih (over heating) dan berpotensi untuk merusak turbin dan sirip-sirip turbin yang pada akhirnya dapat merusak unit pembangkit itu sendiri. Gangguan lain yang sering terjadi pada pembangkit adalah akibat terjadinya kehilangan beban secara mendadak yang mengakibatkan tegangan lebih, dengan demikian tegangan lebih sekecil apapun dapat menaikkan arus eksitasi dan dapat mengakibatkan kerusakan. Berdasarkan dari pemikiran di atas maka penulis bermaksud untuk mengangkat judul penelitian yaitu "Perencanaan Sistem Proteksi Generator dari Putaran Balik di PLTMH Totabuan". Penelitian dilakukan dengan menghitung dan mengatur relay proteksi generator sesuai standar SPLN dan IEEE. Software ETAP 12.6.0 akan digunakan untuk mengatur sistem proteksi pada PLTMH Totabuan. Salah satu contoh untuk perhitungan relay daya balik generator, seperti penelitian yang dilakukan oleh Maria Oktavia Fitriyani UNDIP Semarang 2015 dengan judul evaluasi setting relay proteksi generator dan trafo generator di PLTGU Tambak Lombok Blok 1. Dalam penelitiannya tersebut dilakukan evaluasi waktu kerja relay daya balik pada generator (Fitriyani, 2015). Sedangkan dalam penelitian penulis melakukan perhitungan dan setting relay daya balik dan relay tegangan lebih atau kurang. Untuk perhitungan relay tegangan lebih atau kurang, seperti penelitian yang dilakukan oleh Omer Ozgur Gencer yang berjudul performance of an over/under voltage relay at non-sinusoidal conditions (Gencer, 2006). Berdasarkan penelitian (Gencer, 2006) penulis mengutip cara perhitungan relay tegangan lebih atau kurang.

\section{METEDOLOGI PENELITIAN}

\subsection{Diagram Alur Metode Penelitian (Flowchart)}

Adapun metedologi penelitian penyusun laporan penelitian dijelaskan pada diagram alur sebagai berikut : 


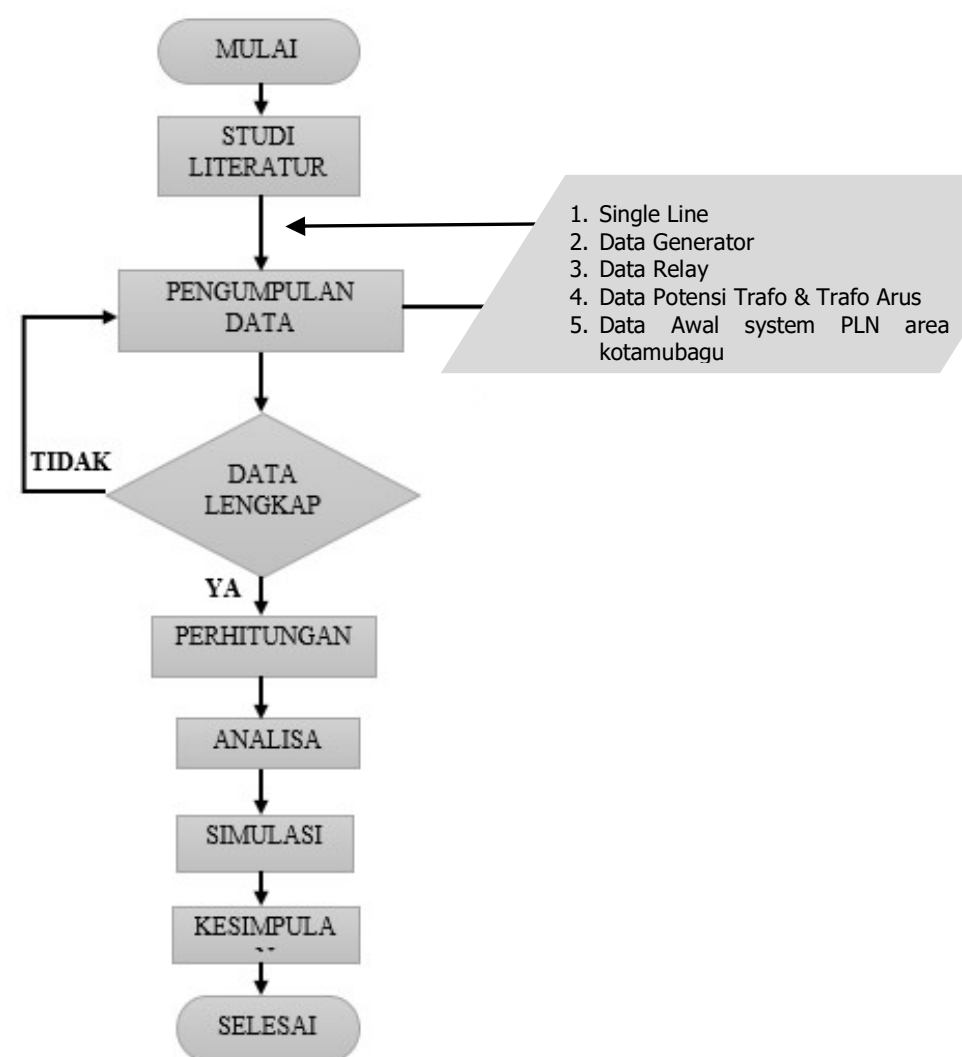

\section{Gambar 1. Diagram Alur Metodologi Penelitian (Flowchart)}

\subsection{Pengolahan Data}

\section{A. Langkah Setting Relay Daya Balik}

Dari data yang didapat maka penulis dapat melakukan perhitungan setting relay daya balik. Pada saat perhitungan yang dilakukan maka penulis menggunakan persamaan :

1. Menghitung arus beban penuh ( $\mathrm{I}_{\mathrm{FL}}$ ) generator (Zuhal, 1991) .

$$
I_{F L}=\frac{S}{V_{L L} \times \sqrt{3}}
$$

Keterangan : $\mathrm{S}=$ Daya Semu Generator (MVA)

$\mathrm{V}_{\mathrm{LL}}=$ Tegangan line to line $(\mathrm{V})$

2. Menentukan ratio CT dan ratio PT.

3. Menghitung daya balik disisi primer.

$$
\text { Daya balik primer }=\text { motoring }(\%) \times M W \text { Generator }
$$

4. Menghitung daya balik disisi sekunder.

$$
\text { Daya balik sekunder }=\frac{\text { Daya balik primer }}{(\text { CT Ratio }) \times(P T \text { Ratio })}
$$

5. Menentukan Time Delay Relay di Unit I dan II.

Untuk mengatur time delay relay, penulis menggunakan standar IEEE C37.102-2006 yaitu dengan waktu tunda relay maksimal 30 detik. Pada penelitian ini penulis menggunakan 
time delay 10 detik, waktu tunda ini digunakan untuk mencegah operasi relay selama ayunan daya yang disebabkan oleh gangguan sistem dan kerja paralel generator.

\begin{tabular}{cc}
\hline Tipe prime mover & $\begin{array}{c}\text { Daya balik dalam \% dari daya rata-rata } \\
\text { generator }\end{array}$ \\
\hline Gas turbine & 50 \\
Diesel engine & 25 \\
Hydro turbine & $0,2-2,0$ \\
Steam turbine & $0,5-3,0$ \\
\hline
\end{tabular}

Gambar 2. Data Daya Balik Berbagai Tipe Turbin (Saputro, 2015)

\section{B. Langkah Setting RelayTegangan Kurang}

1. Untuk relay ini digunakan range $50 \%$ dan $80 \%$ dari tegangan sistem generator (Standar PLN NO. 0357.K/DIR/2014).

2. Rumus untuk menghitung tegangan kurang (Chapman, 1999).

$$
V_{\text {nominal }}=\text { Range } x \text { Tegangan Bus }
$$

3. Dari hasil perhitungan di atas maka penulis melakukan perhitungan waktu kerja relay dengan menggunakan persamaan (Gencer, 2006).

Keterangan :

$$
t=\frac{k \times a}{\left[b \times(1-U / U s)-0,5^{p}\right]}+c
$$

t : Waktu Kerja (detik)

$\mathrm{k} \quad$ : Time Multiplier

$\mathrm{U} / \mathrm{U}_{\mathrm{s}}$ : Multiplies Of Relay Tap Setting

a,b,c : Manufacturer Defined Constants

$\mathrm{p} \quad$ : Inversity Constant

Untuk penentuan relay tegangan kurang penulis menggunakan kurva standart inverse seperti dibawah ini.

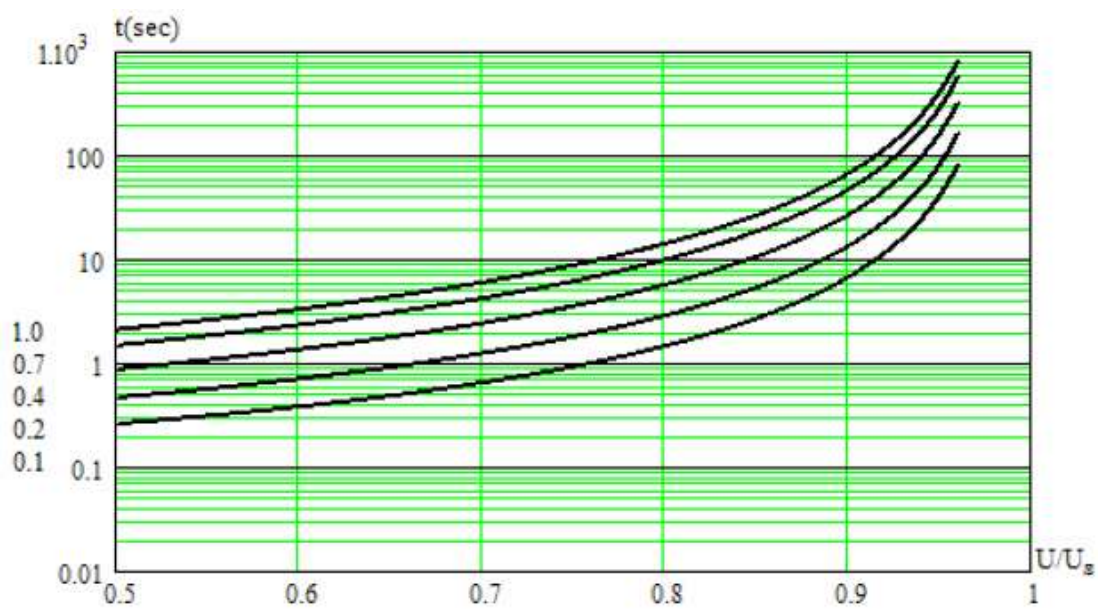

Gambar 3. Kurva Karakteristik Standart Inverse Relay (Sumber: Gencer, 2006) 


\section{Langkah Setting Relay Tegangan Lebih}

1. Untuk relay ini digunakan range mencapai $110 \%$ dan $130 \%$ dari tegangan sistem generator (Standar PLN NO. 0357.K/DIR/2014).

2. Rumus untuk menghitung tegangan lebih menggunakan Persamaan (6).

$$
V_{\text {nominal }}=\text { Range } x \text { Tegangan Bus }
$$

3. Dari hasil perhitungan di atas maka penulis melakukan perhitungan waktu kerja relay dengan menggunakan Persamaan 7 (Gencer, 2006).

$$
t=\frac{k \times a}{\left[b \times\left(U / U s^{-1)}-0,5^{p}\right]\right.}+c
$$

Keterangan :

t : Waktu Kerja (detik)

k : Time Multiplier

$\mathrm{U} / \mathrm{U}_{\mathrm{s}} \quad$ : Multiplies Of Relay Tap Setting

a,b,c : Manufacturer Defined Constants

p : Inversity Constant

Untuk penentuan relay tegangan lebih penulis menggunakan kurva standart inverse seperti Gambar 4.

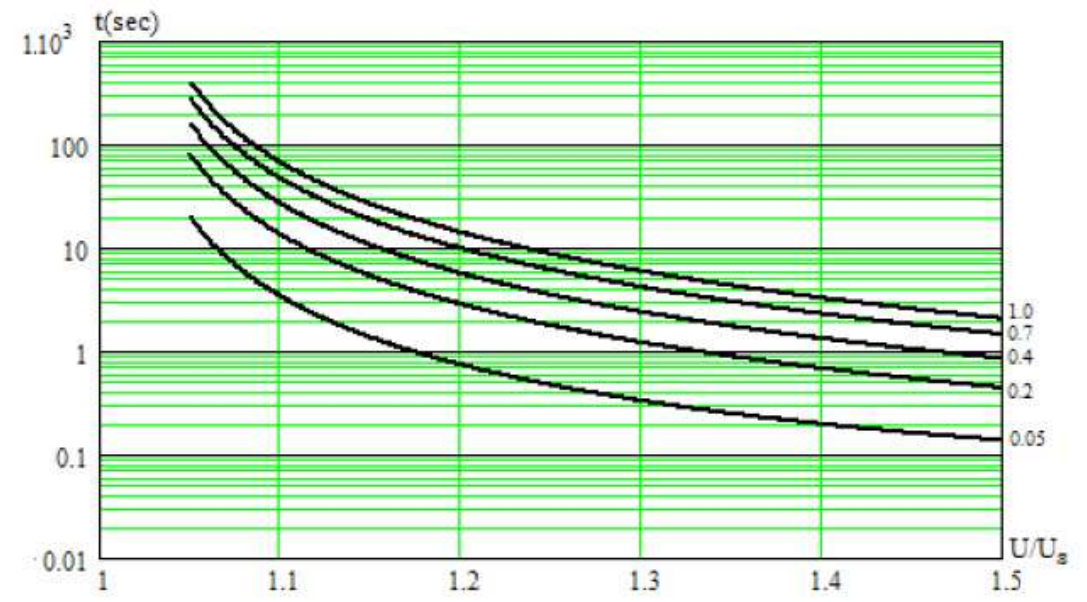

Gambar 4. Kurva Karakteristik Standart Inverse Relay (Sumber: Gencer, 2006)

Ketetapan nilai a, b, c pada Rumus 7 dapat dilihat pada Tabel 1.

Tabel 1. Spesifikasi Kurva Inverse Time

\begin{tabular}{|c|c|c|c|}
\hline Curve & $\mathbf{a}$ & $\mathbf{b}$ & c \\
\cline { 2 - 4 } Description & 3 & 3 & 3 \\
\hline
\end{tabular}




\section{HASIL DAN ANALISIS}

3.1. Data Generator, Current Transformer(CT) dan Potential Transformer(PT) Data generator, CT dan PT yang digunakan pada penelitian ini adalah:

\begin{tabular}{ll} 
Unit I dan II & \\
\hline Capacity & $: 2941 \mathrm{kVA}$ \\
Rating & $: 25 \mathrm{MW}$ \\
\hline Voltage/ Frequency & $: 6300 \mathrm{~V} / 50 \mathrm{~Hz}$ \\
\hline Phase & $: 3 / 0.85 \mathrm{Pf}$ \\
RPM & $: 1500$ \\
\hline Pole & $: 4$ \\
\hline
\end{tabular}

\begin{tabular}{|c|c|}
\hline \multicolumn{2}{|l|}{ Unit III-VI } \\
\hline Capacity & $824 \mathrm{kVA}$ \\
\hline Rating & $0.7 \mathrm{MW}$ \\
\hline Voltage/ Frequency & $6300 \mathrm{~V} / 50 \mathrm{~Hz}$ \\
\hline Phase & $=3 / 0.85 \mathrm{Pf}$ \\
\hline RPM & $: 1500$ \\
\hline Pole & $: 4$ \\
\hline
\end{tabular}

3.2. Perhitungan Relay Daya Balik Pada Unit I dan II

A. Menghitung arus beban penuh $\left(\mathrm{I}_{\mathrm{FL}}\right)$ generator (Persamaan 1):

$$
I_{F L}=\frac{S}{V_{L L} \times \sqrt{3}}=\frac{2941000}{6300 \times \sqrt{3}}=269,52 \mathrm{~A}
$$

\section{B. Daya balik generator :}

Generator unit Totabuan 1\#1 dan generator unit Totabuan $1 \# 2$ menggunakan penggerak mula turbin air. Berdasarkan IEEE std C37.102-2006 daya balik maksimal yang diizinkan mengalir pada generator yaitu $0,2 \%-2 \%$ dari daya yang dibangkitkan generator (Persamaan 2).

Daya balik primer $=2 \% \times 2500000 \mathrm{watt}$

Daya balik primer $=50000$ watt

Daya balik primer $=0,2 \% \times 2500000 \mathrm{watt}=5000$ watt

\section{Daya balik di sisi sekunder :}

Untuk menghitung daya balik di sisi sekunder dilakukan dengan perhitungan (Persamaan 3).

Daya balik sekunder $=\frac{50000 \mathrm{watt}}{(300 / 5) \times(7200 / 120)}$

Daya balik sekunder $=13,8 \mathrm{watt}$

Daya balik sekunder $=\frac{5000 \mathrm{watt}}{(300 / 5) \times(7200 / 120)}=1,38 \mathrm{watt}$

\section{Menentukan time delay/waktu tunda}

Berdasarkan standar IEEE C37.102-2006, waktu tunda relay daya balik maksimal di-setting pada 30 detik. Pada penelitian ini setting relay daya balik digunakan 10 detik, waktu tunda ini digunakan untuk mencegah operasi relay selama ayunan daya yang disebabkan oleh gangguan sistem dan kerja paralel generator.

\subsection{Perhitungan Relay Daya Balik Pada Unit III dan VI}

\section{A. Menghitung arus beban penuh $\left(\mathrm{I}_{\mathrm{FL}}\right)$ generator (Persamaan 1) :} $I_{F L}=\frac{S}{V_{L L} \times \sqrt{3}}=\frac{2941000}{6300 \times \sqrt{3}}=269,52 \mathrm{~A}$ 


\section{B. Daya balik generator :}

Generator unit Totabuan $1 \# 1$ dan generator unit Totabuan $1 \# 2$ menggunakan penggerak mula turbin air. Berdasarkan IEEE std C37.102-2006 daya balik maksimal yang diizinkan mengalir pada generator yaitu $0,2 \%$ - $2 \%$ dari daya yang dibangkitkan generator (Persamaan 2).

Daya balik primer $=2 \% \times 2500000 \mathrm{watt}$

Daya balik primer $=50000$ watt

Daya balik primer $=0,2 \% \times 2500000 \mathrm{watt}=5000$ watt

\section{Daya balik di sisi sekunder :}

Untuk menghitung daya balik di sisi sekunder dilakukan dengan perhitungan (Persamaan 3).

Daya balik sekunder $=\frac{50000 \mathrm{watt}}{(300 / 5) \times(7200 / 120)}=13,8 \mathrm{watt}$

Daya balik sekunder $=\frac{5000 \mathrm{watt}}{(300 / 5) \times(7200 / 120)}=1,38 \mathrm{watt}$

\section{Menentukan time delay/waktu tunda}

Untuk penentuan time delay pada unit III dan VI sama dengan penentuan time delay pada unit I dan II yaitu 10 detik, waktu tunda ini digunakan untuk mencegah operasi relay selama ayunan daya yang disebabkan oleh gangguan sistem dan kerja paralel generator.

\subsection{Perhitungan Setting Relay Tegangan Lebih}

\section{A. Kenaikan Tegangan Pada Saat $\mathbf{1 1 0 \%}$}

Untuk perhiitungan tegangan lebih di saat range $110 \%$ (Persamaan 4).

$V_{\text {maksimum }}=110 \% \times 6300$ volt $=6930$ Volt

Adapun waktu kerja relay dapat ditentukan (Persamaan 5) sebagai berikut :

$t=\frac{1 \times 3}{\left[3 \times(6300 / 6930-1)-0,5^{0,05}\right]}+3=0,57$ detik

Sehingga waktu kerja relay tersebut adalah 0,57 detik ketika kenaikan tegangan pada generator sebesar 6930 volt dengan time multiplier 1.

\section{B. Kenaikan Tegangan Pada Saat $\mathbf{1 3 0 \%}$}

Untuk perhitungan tegangan lebih di saat range 130\% (Persamaan 4).

$V_{\text {maksimum }}=130 \% \times 6300$ volt $=8190$ Volt

Adapun waktu kerja relay dapat ditentukan (Persamaan 5) sebagai berikut :

$t=\frac{1,6 \times 3}{\left[3 \times(6300 / 8190-1)-0,5^{0,05}\right]}+3=0,105$ detik

Sehingga waktu kerja relay tersebut adalah 0,105 detik ketika kenaikan tegangan pada generator sebesar 8190 volt dengan time multiplier 1,6. 
3.5. Perhitungan Setting Relay Tegangan Kurang

A. Penurunan tegangan pada paat $\mathbf{8 0 \%}$

Untuk perhitungan tegangan kurang di saat range $80 \%$ (Persamaan 4).

$V_{\text {maksimum }}=80 \% \times 6300$ volt $=5040$ volt

Adapun waktu kerja relay dapat ditentukan (Persamaan 5) sebagai berikut :

$t=\frac{1 \times 3}{\left[3 \times(1-6300 / 5040)-0,5^{0,1}\right]}+3=1,25$ detik

Sehingga waktu kerja relay tersebut adalah 1,25 detik ketika penurunan tegangan pada generator sebesar 5040 volt dengan time multiplier 1.

\section{B. Penurunan tegangan pada saat $\mathbf{5 0 \%}$}

Untuk perhitungan tegangan kurang di saat range 50\% (Persamaan 4).

$V_{\text {maksimum }}=50 \% \times 6300$ volt $=3150$ volt

Adapun waktu kerja relay dapat ditentukan (Persamaan 5) sebagai berikut :

$t=\frac{3,8 \times 3}{\left[3 \times(1-6300 / 3150)-0,5^{0,1}\right]}+3=0,12$ detik

Sehingga waktu kerja relay tersebut adalah 0,12 detik ketika penurunan tegangan pada generator sebesar 3150 volt dengan time multiplier 3,8.

\subsection{Hasil Simulasi Sofware ETAP 12.6.0}

\section{Skenario pada binterkoneksi diberi gangguang $\mathbf{3}$ fasa}

Pada penelitian ini untuk melihat kerja reverse power relay (32) penulis melakukan dengan simulasi transient stability analysis dengan kondisi relay tegangan tidak diaktifkan. 


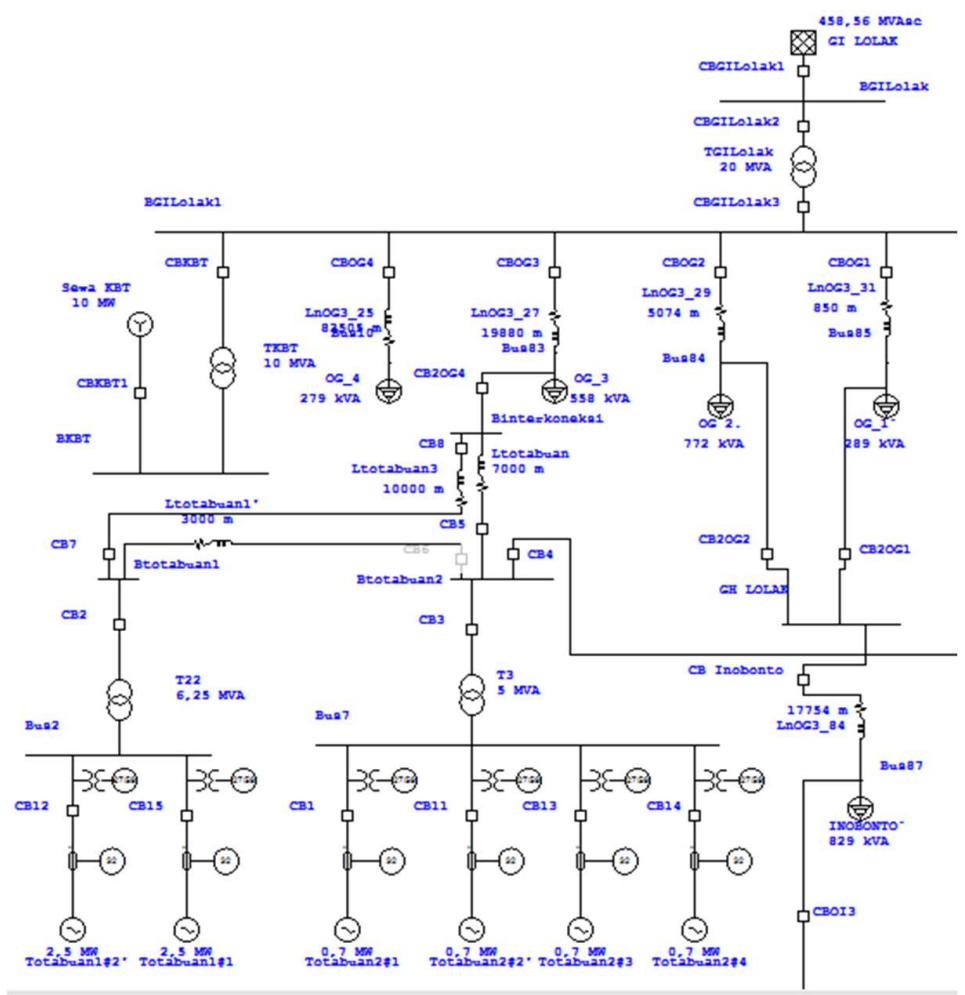

Gambar 5. Single Line PLTMH Totabuan

3.7. Waktu 10 detik dengan Operation Mode Generator Voltage Control Gambar 6 merupakan laporan hasil simulasi transient stability.

\begin{tabular}{|c|c|c|c|c|}
\hline iil Transien & t Stability Acti & on List & $=$ & $1=0$ \\
\hline Time & 0 & \multicolumn{2}{|l|}{80,000 Seconds } & 80,000 \\
\hline 14 & & & & 0 \\
\hline Time (sec) & Event & Device ID & Action & Action By \\
\hline 10,000 & TS & Totabuan1\#1 & Delete & Study Case \\
\hline 40,040 & Dir. Pwr Relay & CB12 & Open & Directional Power Relay \\
\hline 70,090 & Dir. Pwr Relay & CB14 & Open & Directional Power Relay \\
\hline 70,090 & Dir. Pwr Relay & CB13 & Open & Directional Power Relay \\
\hline 70,090 & Dir. Pwr Relay & CB11 & Open & Directional Power Relay \\
\hline 70,090 & Dir. Pwr Relay & CB1 & Open & Directional Power Relay \\
\hline
\end{tabular}

Gambar 6. Data Hasil Simulasi Transient Stability 


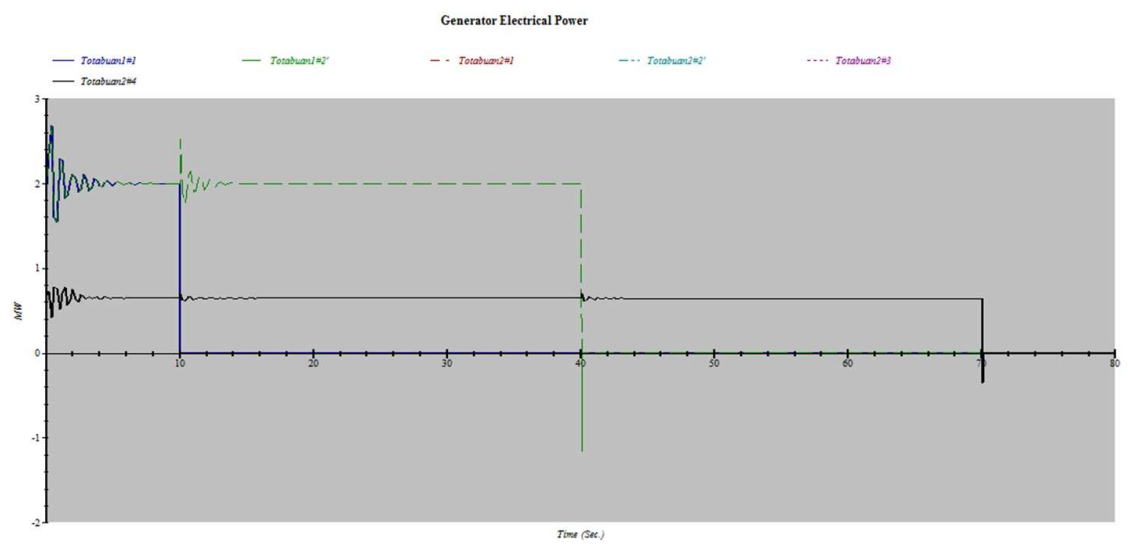

Gambar 7. Kurva Daya Generator Terhadap Waktu

Percobaan ini penulis mengatur time delay relay (32) 30 detik ketika pick-up $0,2 \%$ dan $2 \%$. Bila dilihat Gambar 7 pada kurva generator Totabuan 1\#1 dan Totabuan $1 \# 2$ saat waktu 0 sampai 6 detik adalah gelombang waktu kerja generator saat dioperasikan. Untuk generator Totabuan $2 \# 1,2 \# 2$, 2\#3, dan $2 \# 4$ saat 0 sampai 5 detik adalah gelombang waktu kerja generator saat dioperasikan. Kemudian kurva generator Totabuan $1 \# 1$ dan $1 \# 2$ dari waktu 6 sampai 10 detik daya generator stabil (steady state), dan untuk generator Totabuan 2\#1, 2\#2, 2\#3, 2\#4 saat waktu 5 sampai 10 detik daya generator stabil (steady state). Saat waktu 10 detik generator Totabuan $1 \# 1$ trip sehingga saat waktu 10,01 terjadi osilasi hingga mencapai 2,6 MW kemudian turun secara perlahan sampai mencapai steady state generator. Akibat terjadi osilasi hingga mencapai 2,6 MW maka relay daya balik (32) mendeteksi terjadinya gangguan sehingga pada waktu 40,04 detik CB12 trip (open). Akibat generator Totabuan $1 \# 1$ trip maka terjadi osilasi saat 10,01 detik sampai 16 detik pada generator Totabuan $2 \# 1$, 2\#2, 2\#3, 2\#4. Kemudian disaat waktu 40,04 detik generator Totabuan $1 \# 2$ trip sehingga terjadi pengulangan osilasi mencapai $0,85 \mathrm{MW}$ kemudian menurun sampai mencapai titik steady state, akibat hal tersebut maka relay daya balik (32) pada generator Totabuan 2\#1, 2\#2, 2\#3, 2\#4 mendeteksi adanya gangguan sehingga pada waktu 70,09 detik CB14, CB13, CB11, CB1 dalam kondisi terbuka (open).

Gambar 8 merupakan hasil simulasi kurva tegangan di bus 2 dan bus 7.

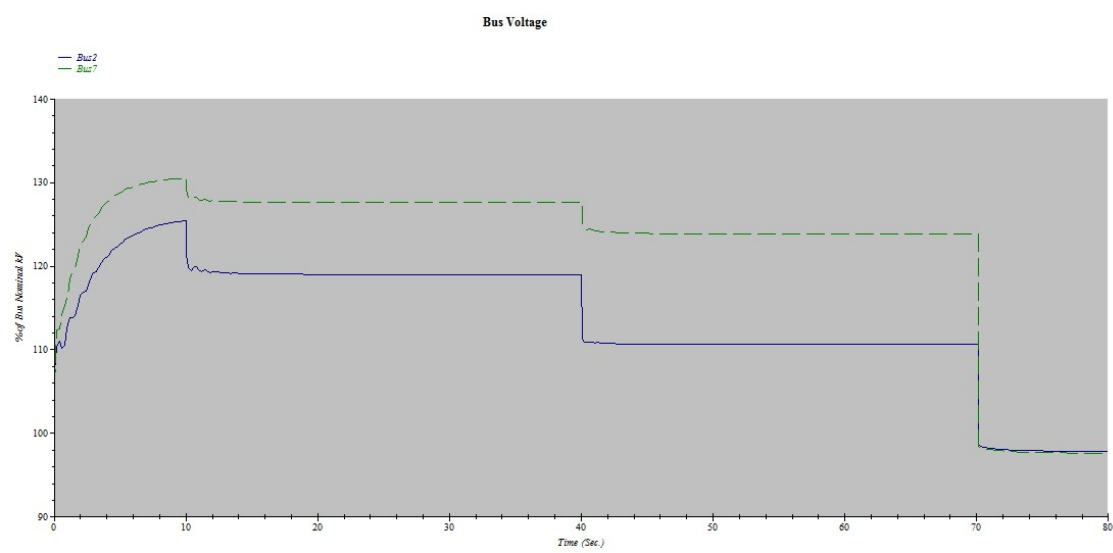

Gambar 8. Kurva Tegangan di bus 2 dan bus 7

Efek lain dari percobaan yang dilakukan dapat mempengaruhi tegangan pada bus generator. Untuk melihat tegangan yang terjadi saat gangguan dapat dilihat pada Gambar 8. Untuk kurva bus7 saat waktu 0 detik sampai 10 detik tegangan mengalami kenaikan sampai $131 \%$ dari 
tegangan nominal bus, hal ini disebabkan karena osilasi waktu kerja generator (dapat dilihat Gambar 7). Kemudian saat waktu 10 detik mengalami penurunan hingga mencapai $128 \%$ dari tegangan nominal bus. Saat waktu 40 detik tegangan kembali mengalami penurunan sampai mencapai 125,8\% dari tegangan nominal bus, hal ini disebabkan CB trip. Saat waktu 70,09 detik, tegangan kembali mengalami penurunan hingga mencapai $100 \%$ dari tegangan bus, bila dilihat tegangan tidak turun sampai $0 \%$ karena bus masih terhubung ke jaringan sistem. Untuk tegangan pada bus 2 bila dilihat Gambar 8 . Untuk kurva bus 2 saat waktu 0 detik sampai 10 detik tegangan mengalami kenaikan sampai 127,8\% dari tegangan nominal bus, hal ini disebabkan karena osilasi waktu kerja generator (dapat dilihat Gambar 7). Kemudian saat waktu 10 detik mengalami penurunan hingga mencapai 119,5\% dari tegangan nominal bus. Saat waktu 40 detik tegangan kembali mengalami penurunan sampai mencapai $110 \%$ dari tegangan nominal bus, hal ini disebabkan CB trip. Saat waktu 70,09 detik, tegangan kembali mengalami penurunan hingga mencapai $100 \%$ dari tegangan bus, bila dilihat tegangan tidak turun sampai $0 \%$ karena bus masih terhubung ke jaringan sistem.

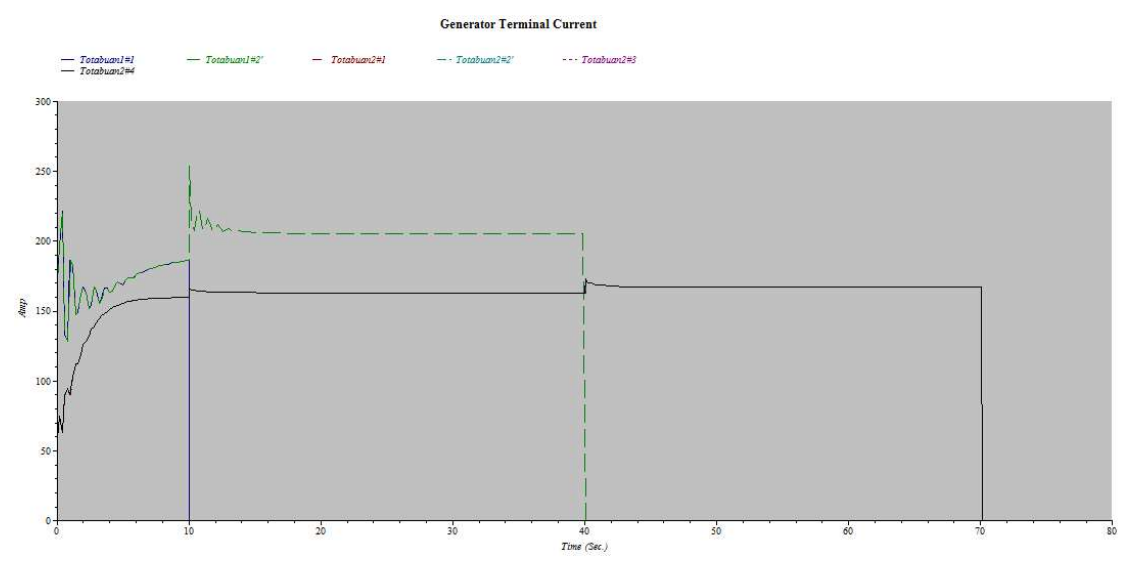

Gambar 9. Kurva Arus Generator Terhadap Waktu

Pengaruh saat terjadi gangguan untuk kurva arus generator Totabuan $1 \# 1$ dan $1 \# 2$ saat waktu 0,03 detik terjadi kenaikan arus hingga mencapai 251 ampere kemudian turun dan mengalami osilasi hingga waktu 6,3 detik. Saat 6,31 detik arus secara perlahan mengalami kenaikan hingga mencapai 177 ampere. Karena generator Totabuan $1 \# 1$ saat waktu 10 detik trip maka arus turun hingga mencapai 0 ampere, akibat generator trip maka arus generator Totabuan 1\#2 mengalami osilasi hingga 250,2 ampere kemudian mengalami penurunan secara perlahan sampai 220 ampere. Saat waktu 40 detik generator trip dan arus pada generator menurun sampai titik 0 ampere. Untuk kurva generator Totabuan 2\#1, 2\#2, 2\#3, 2\#4 saat waktu 0 detik arus mulai dari 52,2 ampere, kemudian naik secara perlahan hingga mencapai 151, 8 ampere, kenaikan arus ini disebabkan karena osilasi yang terjadi (dapat dilihat gambar 7). saat waktu 10,1 detik arus naik 152,2 ampere. Saat waktu 40 detik generator Totabuan 1\#2 trip dan mengakibatkan arus generator Totabuan 2\#1, 2\#2, 2\#3, 2\#4 naik hingga mencapai 154, 9 ampere, dan saat waktu 70,09 detik generator trip dan arus juga ikut turun hingga mencapai 0 ampere.

\subsection{Skenario Gangguan 3 Fasa di bus Binterkoneksi}

Pada percobaan relay tegangan dilakuakn simulasi Protective Divice Coordination dengan gangguan 3 fasa. Gambar 10 merupakan hasil simulasi Protective Divice Coordination dengan gangguan 3 fasa. 


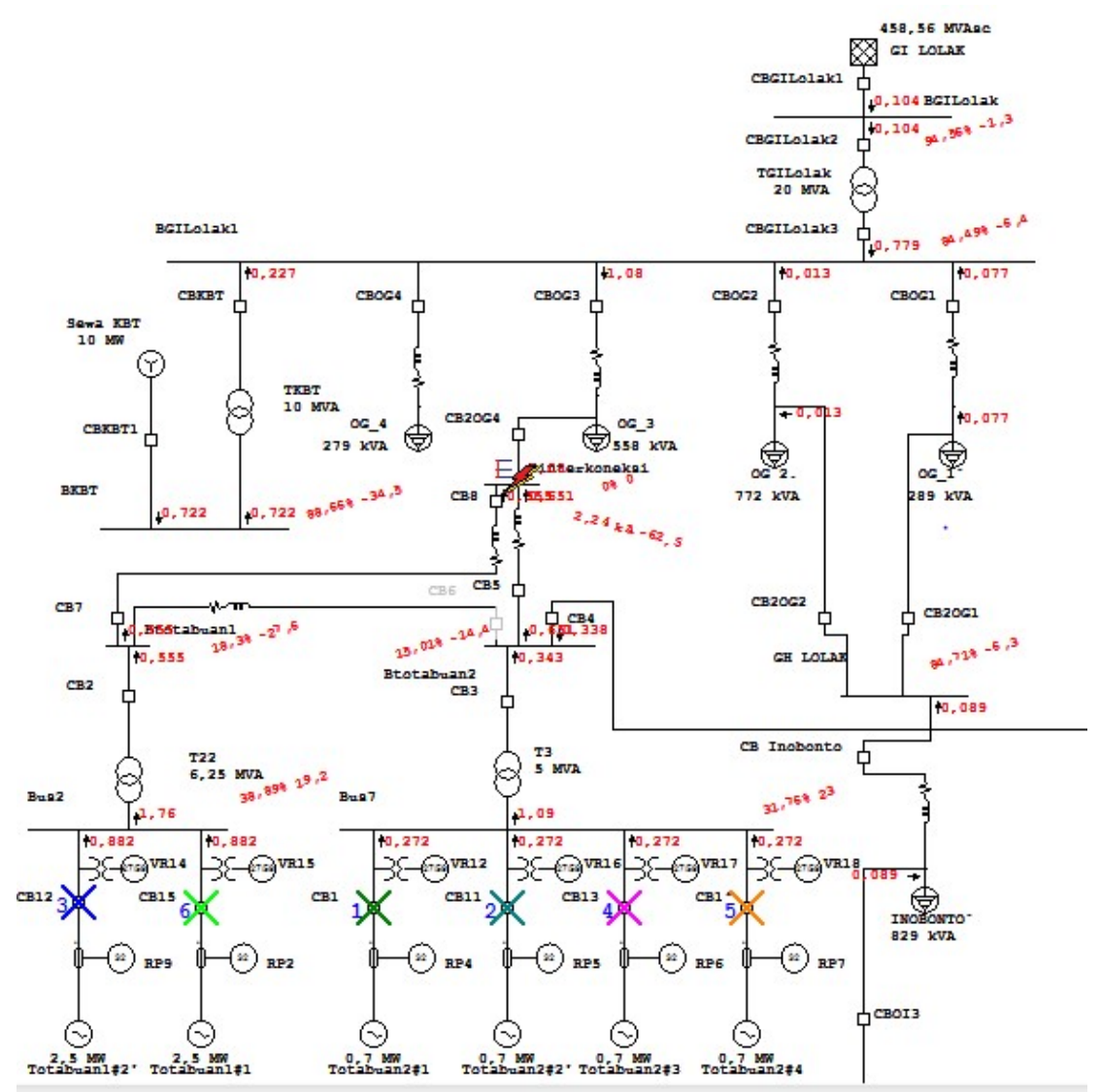

Gambar 10. Single Line Saat Percobaan Short Circuit 3 Fasa

Gambar 11 merupakan laporan waktu hasil simulasi software ETAP 12.6.0. Diberikan gangguan 3 fasa pada bus binterkoneksi kemudian tegangan yang terbaca pada bus 7 yaitu $31,76 \%$ dan untuk bus 2 tegangan yang terbaca saat gangguan 3 fasa yaitu 38,89\% dari tegangan nominal bus. Sehingga saat waktu 0,12 detik relay tegangan kurang (VR12, VR14, VR15, VR16, VR17, VR18) mendeteksi ada gangguan di bus generator, sehingga relay memerintahkan CB1, CB11, CB12, CB13, CB14, CB15 trip (open) kemudian saat waktu 0,13 detik $C B$ trip. Saat waktu 0,125 detik relay tegangan kembali mendeteksi adanya tegangan kurang dengan range $80 \%$ dari tegangan nominal bus.

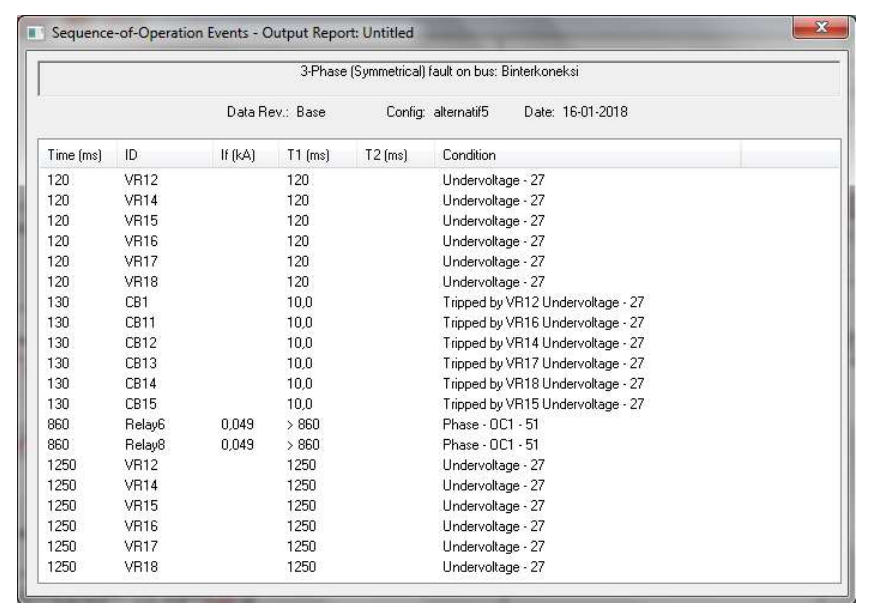

Gambar 11. Hasil Laporan Simulasi Gangguan 3 Fasa di bus Binterkoneksi 


\subsection{Skenario Gangguan 3 Fasa di bus 2}

Gambar 12 merupakan hasil simulasi Protective Divice Coordination dengan gangguan 3 fasa.

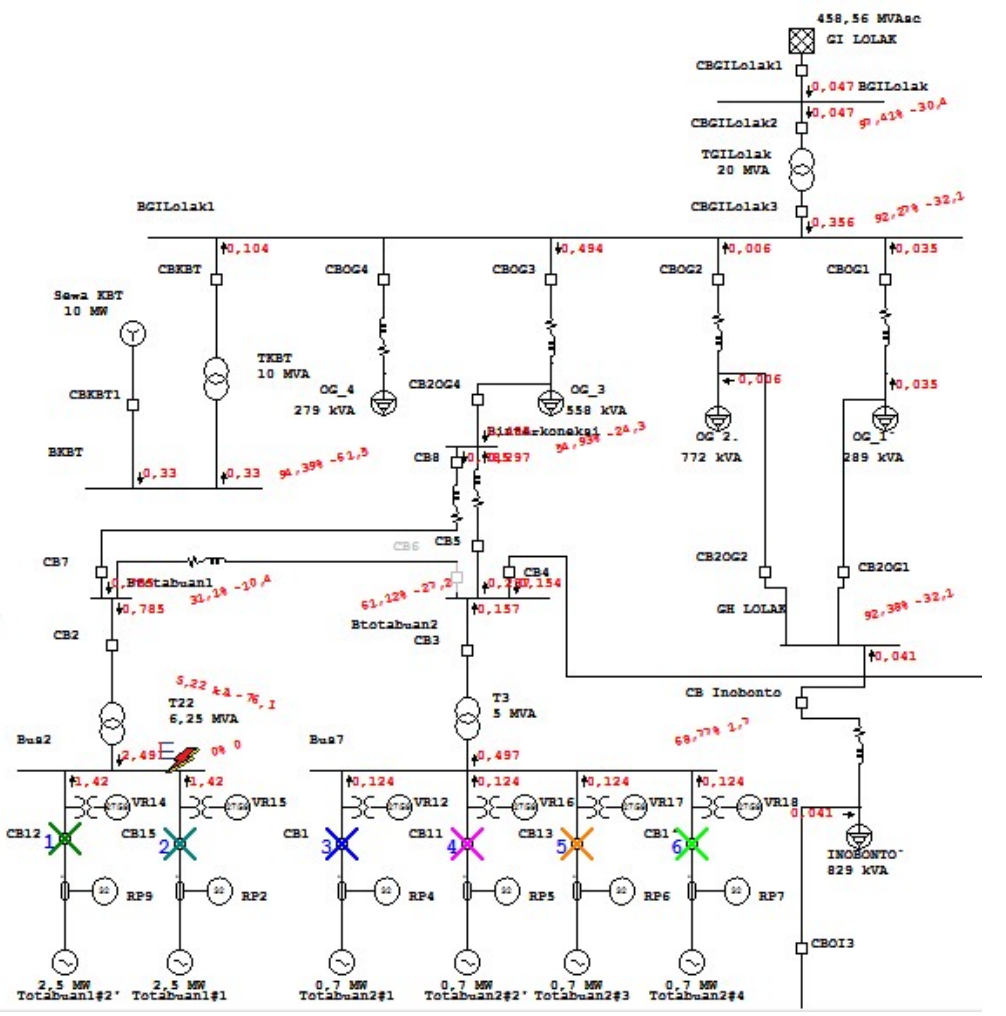

Gambar 12. Single Line Saat Percobaan Short Circuit 3 Fasa di bus 2

Gambar 13 merupakan laporan waktu hasil simulasi software ETAP 12.6.0. Bila dilihat hasil simulasi saat gangguan 3 fasa diberikan di bus 2, tegangan yang terbaca di bus 2 yaitu $0 \%$ dan di bus 7 68,77\% dari tegangan nominal bus. Sehingga saat waktu 0,12 detik relay tegangan pada bus 2 mendeteksi gangguan tegangan kurang range $50 \%$ dari tegangan bus dan saat waktu 0,13 detik CB12, CB15 trip. Kemudian saat waktu 1,25 detik relay tegangan (VR12, VR13, VR14, VR15, VR16, VR17, VR18) mendeteksi tegangan kurang. Untuk relay tegangan pada bus 7 mendeteksi tegangan kurang range $80 \%$ sehingga relay mendeteksi gangguan dan saat waktu 1,26 detik CB1, CB11, CB13, CB14 trip.

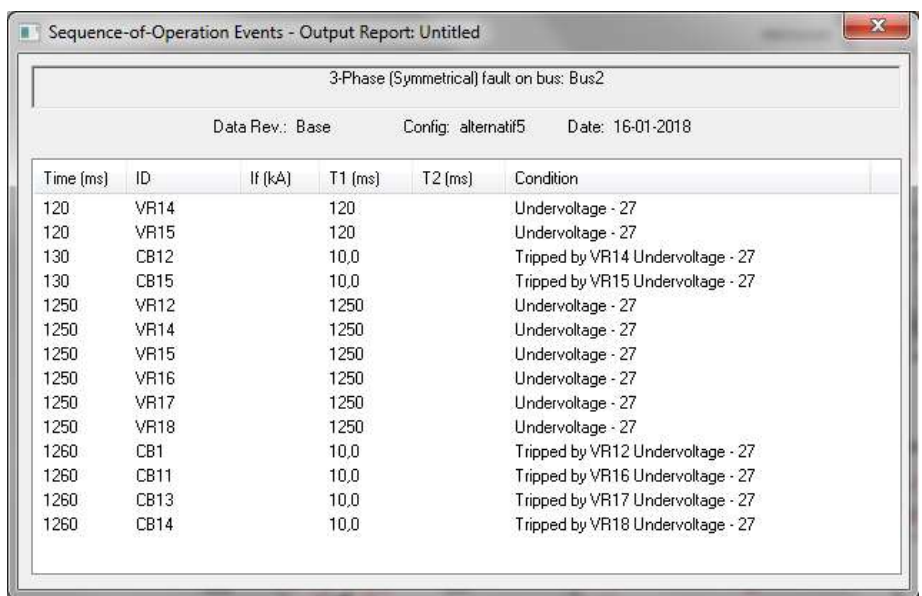

Gambar 13. Hasil Laporan Simulasi Gangguan 3 Fasa di bus 2 


\subsection{Skenario Gangguan 3 Fasa di bus 7}

Gambar 14 merupakan hasil simulasi Protective Divice Coordination dengan gangguan 3 fasa.

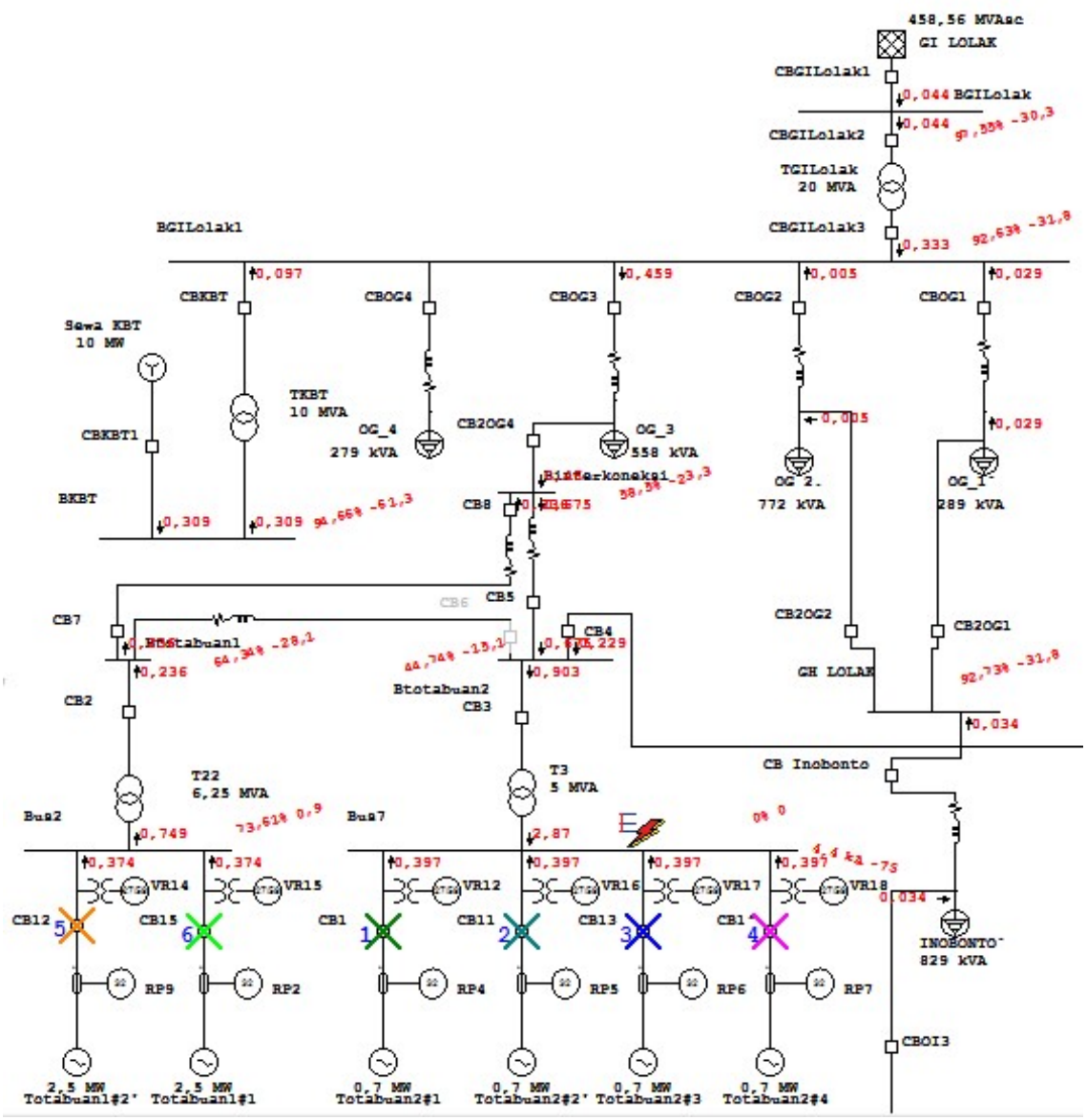

Gambar 14. Single Line Saat Percobaan Short Circuit 3 di bus 7

Gambar 15 merupakan laporan waktu hasil simulasi software ETAP 12.6.0.

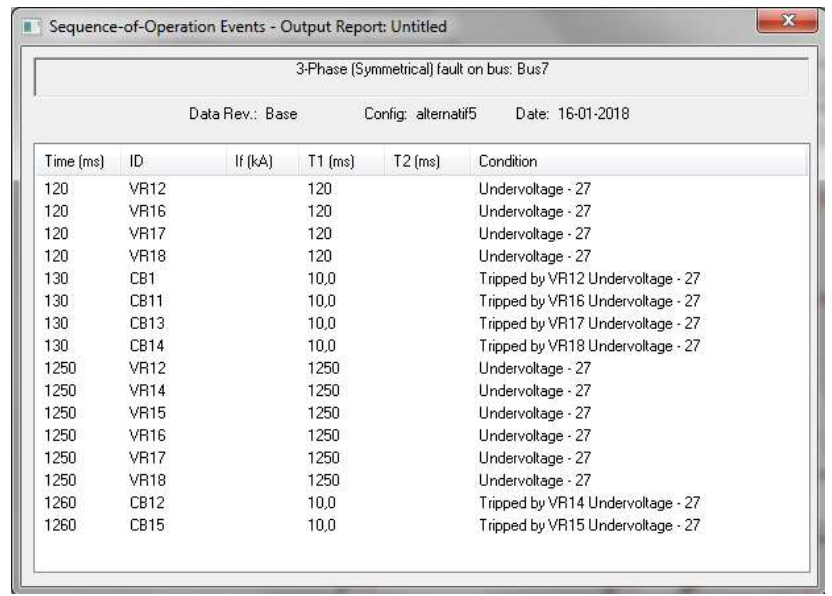

Gambar 15. Hasil Laporan Simulasi Gangguan 3 Fasa di bus 7

Saat diberi gangguan 3 fasa pada bus 7 tegangan yang terbaca di bus 7 yaitu $0 \%$ dan bus 2 73,61\% dari tegangan nominal bus. Saat waktu 0,12 detik relay tegangan (VR12, VR16, VR17, 
VR18) mendeteksi tegangan kurang sehingga saat waktu 0,13 detik CB1, CB11, CB13, CB14, trip. Dan ketika waktu 1,25 detik relay tegangan (VR14, VR15) pada bus 2 mendeteksi tegangan kurang range $80 \%$ sehingga saat waktu 1,26 detik CB12, CB15 trip.

\section{KESIMPULAN}

Kesimpulan yang dapat diambil dalam penelitian penelitian ini adalah sebagai berikut :

1. Berdasarkan hasil perhitungan maka setting relay over voltage (59) saat simulasi kenaikan tegangan $110 \%$ adalah 0,57 detik dan saat kenaikan $130 \%$ adalah 0,105 detik. Sedangkan untuk relay under voltage (27) saat turun tegangan $50 \%$ adalah 0,125 detik dan saat turun tegangan $80 \%$ adalah 1,25 detik. Sehingga apabila dibandingkan hasil perhitungan dengan standar PLN tidak jauh berbeda, untuk SPLN no.0357.K/DIR/2014 saat relay over voltage $110 \%$ adalah 2 detik dan saat $130 \%$ adalah 0,1 detik kemudian untuk settingan relay under voltage saat $50 \%$ adalah 0,1 detik dan saat $80 \%$ adalah 1 detik.

2. Untuk setting relay daya balik (32) penulis menggunakan standart IEEE C37.102-2006. Menurut standart IEEE waktu tunda yang diizinkan maksimal 30 detik. Setting generator kapasitas 2,5 MW dan 0,7 MW waktu tundanya dilakukan hingga beberapa percobaan antara lain 1-30 detik. Hal ini bertujuan untuk mengetahui waktu kerja relay yang tepat saat terjadi gangguan. Setelah dilakukan percobaan penulis menyimpulkan waktu tunda relay daya balik adalah 10 detik dengan pick-up $2 \%$ dari daya yang dibangkitkan generator.

3. Berdasarkan analisis yang dilakukan penulis, tegangan antar generator harus dijaga konstan agar daya yang dibangkitkan generator stabil. Selain itu frekuensi juga harus dipertahankan konstan agar tidak terjadi daya balik, sesuai dengan teori dasar tentang syarat sinkronisasi pada generator paralel.

\section{DAFTAR RUJUKAN}

Fitriyani, M. O. (2015). Evaluasi Setting Relay Proteksi Generator dan Trafo Generator Di PLTGU Tambak Lorok Blok I. Semarang: Teknik Elektro Universitas Diponogoro.

Gencer, O. O. (2006). "Performance Of an Over/Under Voltage Relay at Non-sinusoidal Conditions". Jurnal IEEE. Spain. (Pp. 1103)

Saputro, T. D. (2015). Evaluasi Setting Relay Proteksi Generator Pada Plan PT. Petrochina International Jabung Ltd. Betara Complex Development Project Menggunakan Simulasi ETAP 12.6.0. Semarang: Teknik Elektro Universitas Diponogoro.

Standar PLN NO. 0357.K/DIR/2014 - "Pedoman Penyambungan Pembangkit Listrik Energi Terbarukan Ke Sistem Distribusi PLN".

Zuhal. (1991). Dasar Tenaga Listrik. Bandung: Institut Teknologi Bandung.

Chapman, S. J. (1999). Electrical Machinery Fundamentals. New York: Mc Graw-hill. 